\title{
Synthesis and Antioxidative Potency of Novel Amidino Substituted Benzimidazole and Benzothiazole Derivatives
}

Livio Racané, ${ }^{1}$ Maja Cindrić, ${ }^{2}$ Nataša Perin, ${ }^{2}$ Petra Roškarić, ${ }^{2}$ Kristina Starčević, ${ }^{3, *}$ Tomislav Mašek, ${ }^{4}$ Maja Maurić, ${ }^{3}$ Jasna Dogan, ${ }^{5}$ Grace Karminski-Zamola ${ }^{2, \#}$

\footnotetext{
Department of Applied Chemistry, Faculty of Textile Technology, University of Zagreb, Prilaz baruna Filipovića 28a, 10000 Zagreb, Croatia

2 Department of Organic Chemistry, Faculty of Chemical Engineering and Technology, University of Zagreb, Marulićev trg 19, 10000 Zagreb, Croatia

3 Department of Animal Husbandry, Faculty of Veterinary Medicine, University of Zagreb, Heinzelova 55, HR-10000 Zagreb, Croatia

${ }^{4}$ Department of Animal Nutrition and Dietetics, Faculty of Veterinary Medicine, University of Zagreb, Heinzelova 55, 10000 Zagreb, Croatia

5 Pliva - TAPI R\&D Chemistry, Prilaz baruna Filipovića 29, 10000 Zagreb, Croatia

* Corresponding author's e-mail address: kstarcevic@vef.hr

\# Corresponding author's e-mail address: gzamola@fkit.hr
}

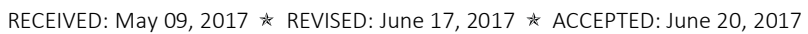

THIS PAPER IS DEDICATED TO PROF. MIRJANA METIKOŠ-HUKOVIĆ ON THE OCCASION OF HER BIRTHDAY

Abstract: Herein we present the synthesis of versatile amidino substituted benzothiazole 3-10 and benzimidazole 12-19 derivatives substituted with the variable number of hydroxy and methoxy groups. Furthermore, the synthesized compounds were explored for their antioxidative activity in vitro by using three biological assays, namely DPPH, ABTS and FRAP. The obtained results indicated that the variable number of hydroxy groups together with the type of the amidino substituent strongly influenced the antioxidative activity and reducing power of tested compounds. The most promising antioxidative activity showed trihydroxy substituted compounds $6,10,15$ and 19 . In general, it was noticed that unsubstituted amidino group induced the more pronounced activity in comparison to derivatives bearing 2 -imidazolinyl group.

Keywords: amidines, benzimidazoles, benzothiazoles, antioxidative activity in vitro.

\section{INTRODUCTION}

B ENZIMIDAZOLES and benzothiazoles, amongst all nitrogen heterocycles, are one of the most important building motifs of many essential and physiologically active natural, semisynthetic or synthetic pharmaceuticals.[1] Being fundamental structural parts of a number of biologically active derivatives, there has been an increasing interest in medicinal chemistry in the role of both heterocycles due to their possible pharmacological, chemical or industrial applications. ${ }^{[2,3]}$ Their derivatives display a broad spectrum of different biological features such as anticancer, antiviral, antibacterial, antifungal, antiinflammatory etc. ${ }^{[4-6]}$

In our research group we have published several publications regarding antiproliferative and antitumor activity of versatile benzimidazole and benzothiazole derivatives bearing different amidino supstituents. ${ }^{[7,8]}$ Among all amidino substituted benzazole derivatives, the ones with the cyclic amidino substituent, namely 2imidazolinyl group, showed the most significant antiproliferative activity in vitro with $\mathrm{IC}_{50}$ values in submicromolar range of concentrations. ${ }^{[9]}$ Almost all previously synthesized active derivatives have been designed to have cationic amidino substituents which have significantly improve their biological activity. Amidine substituents placed at the termini of the molecule have great importance in the molecule - biological target interactions allowing the formation of the stable complex with biologically important molecules. Also, 2-imidazolinyl substituted tetracyclic benzimidazole derivatives showed pronounced selectivity towards colon carcinoma cells being

(cc) Br 

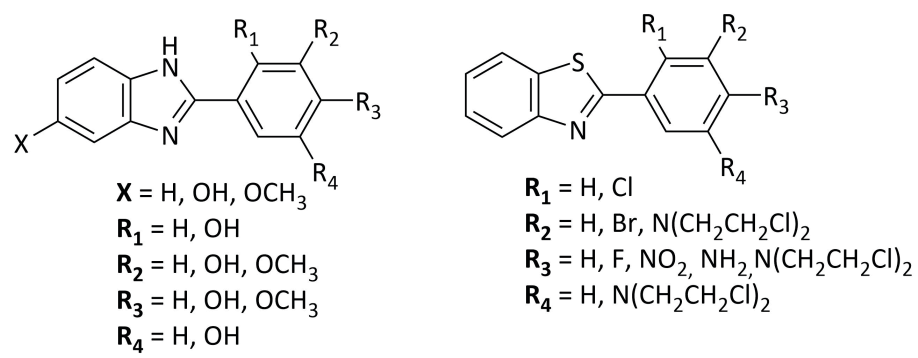

Figure 1. Benzimidazole and benzothiazole derivatives with antioxidative activity

strong DNA intercalators and inhibited human topoisomerase II. ${ }^{[10]}$ On the other hand, acyclic benzimidazoles and benzothiazoles have been proven to be a selective DNA minor groove binders which was confirmed with several spectroscopic methods. Regarding the 2-phenylbenzothiazole derivatives, we have shown that their antiproliferative activity strongly depends on the type of amidino group as well as on their position on the targeted molecule. ${ }^{[7,9]}$ Nowadays, the attention of medicinal chemists is focused also on the development of the novel antioxidative agents, especially after it has been evidenced that oxidative damage of important biomacromolecules is directly connected with the pathogenesis of various diseases. ${ }^{[11,12]}$ Thus, the reactive oxygen species (ROS) through the damage of cellular biomacromolecules like proteins, lipids or DNA/RNA may be playing an important role in the development of cancer, atherosclerosis, aging or rheumatoid arthritis. ${ }^{[13,14]}$ One of the chain reactions caused by ROS is lipid peroxidation which could generate mutagenic products with carcinogenic properties. ${ }^{[15]}$ Many natural and synthetic products possess antioxidative capacity and are studied as a promising antioxidants which could reduce the rate of ROS production and the oxidation of biomacromolecules. ${ }^{[16]}$ Several publications described the antioxidative activity and potential of benzimidazole and benzothiazole derivatives as antioxidative agents. B. Zhou and co-authors have been published the antioxidative activity of a series of 2-aryl benzimidazole derivatives (Figure 1). ${ }^{[17]}$ Obtained results revealed that derivative bearing a hydroxy group at the 5-position of benzimidazole nuclei posses a comparable or better antioxidant activity in comparison to standard antioxidant tert-butylhydroquinone (TBHQ). On the other hand a series of 2-aryl substituted benzothiazoles (Figure 1) has also show antioxidative activity and significant radical scavenging potential due to the presence of electron donating substituent. ${ }^{[18]}$

All the above mentioned facts guided us to design and synthesize novel amidino substituted benzazole derivatives in order to evaluate their antioxidant potential. The obtained results are discussed in terms of SAR to define the influence of the type of amidino group and heterocyclic nuclei as well as the number of hydroxy groups attached on the phenyl ring on the antioxidative activity of prepared derivatives.

\section{EXPERIMENTAL PART \\ Chemistry \\ GENERAL METHODS}

Melting points were determined by means of Original Kofler Mikroheitztisch apparatus (Reichert, Wien). The ${ }^{1} \mathrm{H}$ NMR and the ${ }^{13} \mathrm{C}$ NMR spectra were recorded with the Bruker Avance DPX-300 or Bruker AV-600 using TMS as internal standard. Chemical shifts are reported in parts per million ( $\mathrm{ppm}$ ) relative to TMS. LC-MS was performed on the Agilent 6120 Quadrupole coupled to the Agilent 1290 Infinity II UHPLC using electrospray ionization (ESI).

\section{SYNTHESIS}

Synthesis of 2-amino-5-amidiniumbenzenethiolate $\mathbf{2 a}$ and 2-amino-5-(4,5-dihydro-1H-imidazol-3-ium-2-yl)benzenethiolate hydrate $\mathbf{2} \mathbf{b}$ were carried out according to the literature. ${ }^{[19]}$ Synthesis of 4-amidinium-1,2-phenylenediamine 11a and 2-(3,4-diaminophenyl)-4,5-dihydro- $1 \mathrm{H}$ imidazol-3-ium chloride $\mathbf{1 1} \mathbf{b}$ were carried out according to the literature. ${ }^{[20]}$

\section{General method for the synthesis of benzothiazole derivatives 3-10}

A mixture of the corresponding aldehyde $1 \mathbf{a}-\mathbf{1 d}(0.5 \mathrm{mmol})$ and 2-amino-5-amidiniumbenzenethiolate $2 \mathrm{a}(0.5 \mathrm{mmol})$ or 2-amino-5-(4,5-dihydro-1H-imidazol-3-ium-2-yl)benzenethiolate hydrate $\mathbf{2 b}(0.5 \mathrm{mmol})$ in glacial acetic acid $(5 \mathrm{~mL})$ was stirred at reflux under nitrogen for $3 \mathrm{~h}$, followed by the addition of concentrated hydrochloric acid $(0.5 \mathrm{~mL})$ and additionally stirred at room temperature for $1 \mathrm{~h}$. After cooling overnight, the crude product was filtered off, washed with acetone and crystallized to obtain pure compounds $\mathbf{3} \mathbf{- 1 0}$.

6-Amidinium-2-(2-hydroxyphenyl)benzothiazole chloride 3 Using above described method from 2-hydroxybenzaldehyde 1a (0.061 g, 0.5 mmol), 2-amino-5-amidiniumben- 
zenethiolate $2 \mathrm{a}(0.084 \mathrm{~g}, 0.5 \mathrm{mmol})$ and crystallization from $0.1 \mathrm{M}$ hydrochloric acid/acetone mixture was obtained $0.089 \mathrm{~g}$ (58.2 \%) of colourless solid, m.p. $292-296{ }^{\circ} \mathrm{C} ;{ }^{1} \mathrm{H}$

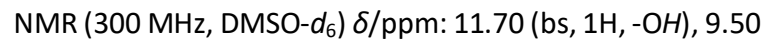
$\left(\mathrm{s}, 2 \mathrm{H},-\mathrm{C}\left(\mathrm{NH}_{2}\right)_{2}{ }^{+}\right), 9.28\left(\mathrm{~s}, 2 \mathrm{H},-\mathrm{C}\left(\mathrm{NH}_{2}\right)_{2}{ }^{+}\right), 8.69(\mathrm{~d}, 1 \mathrm{H}, J=1.6$ $\mathrm{Hz}, \mathrm{Ar}-H), 8.34(\mathrm{dd}, 1 \mathrm{H}, J=8.0 \mathrm{~Hz}, J=1.6 \mathrm{~Hz}, \mathrm{Ar}-H), 8.23(\mathrm{~d}$, $1 \mathrm{H}, J=8.6 \mathrm{~Hz}, \mathrm{Ar}-H), 7.93(\mathrm{dd}, 1 \mathrm{H}, J=8.6 \mathrm{~Hz}, J=1.9 \mathrm{~Hz}$, Ar$H), 7.46(\mathrm{~m}, 1 \mathrm{H}, \operatorname{Ar}-H), 7.20(\mathrm{~d}, 1 \mathrm{H}, J=7.7 \mathrm{~Hz}, \operatorname{Ar}-H), 7.05(\mathrm{~m}$, $1 \mathrm{H}, \mathrm{Ar}-H) ;{ }^{13} \mathrm{C}$ NMR (75 MHz, DMSO- $d_{6}$ ) $\delta / \mathrm{ppm}: 167.9$, 165.6, 156.7, 154.7, 135.2, 133.1, 128.6, 125.9, 123.9, 123.0, 122.2, 119.7, 118.6, 117.0; LC-MS (ESI) m/z: 270.0 $\left[\left(\mathrm{M}-\mathrm{Cl}^{-}\right)^{+}\right]$.

\section{6-Amidinium-2-(2,4-dihydroxyphenyl)benzothiazole chloride 4}

Using above described method from 2,4-dihydroxybenzaldehyde $1 \mathrm{~b}$ (0.069 g, $0.5 \mathrm{mmol}$ ), 2-amino-5-amidiniumbenzenethiolate $2 \mathrm{a}(0.084 \mathrm{~g}, 0.5 \mathrm{mmol})$ and crystallization from $0.1 \mathrm{M}$ hydrochloric acid was obtained $0.083 \mathrm{~g}$ (51.8\%) of beige solid, m.p. $>300{ }^{\circ} \mathrm{C} ;{ }^{1} \mathrm{H}$ NMR (300 MHz, DMSO- $d_{6}$ )

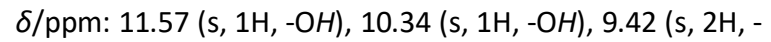
$\left.\mathrm{C}\left(\mathrm{NH}_{2}\right)_{2}{ }^{+}\right), 9.14\left(\mathrm{~s}, 2 \mathrm{H},-\mathrm{C}\left(\mathrm{NH}_{2}\right)_{2}{ }^{+}\right), 8.59(\mathrm{~s}, 1 \mathrm{H}, \mathrm{Ar}-\mathrm{H}), 8.14-$ $8.10(\mathrm{~m}, 2 \mathrm{H}, \mathrm{Ar}-H), 7.88(\mathrm{~d}, 1 \mathrm{H}, J=8.6 \mathrm{~Hz}, \operatorname{Ar}-H), 6.57(\mathrm{~s}, 1 \mathrm{H}$, $\operatorname{Ar}-H), 6.49(\mathrm{~d}, 1 \mathrm{H}, J=8.7 \mathrm{~Hz}, \operatorname{Ar}-H) ;{ }^{13} \mathrm{C} \mathrm{NMR}(75 \mathrm{MHz}$, DMSO- $d_{6}$ ) $\delta / p p m: 168.9,165.5,162.3,158.5,154.9,134.3$, 130.1, 125.7, 123.1, 122.5, 121.2, 110.4, 108.6, 102.6; LCMS (ESI) $m / z: 286.1\left[\left(\mathrm{M}-\mathrm{Cl}^{-}\right)^{+}\right]$.

\section{6-Amidinium-2-(2-hydroxy-4-methoxyphenyl)benzothia-} zole chloride 5

Using above described method from 2-hydroxy-4methoxybenzaldehide $1 c$ ( $0.076 \mathrm{~g}, 0.5 \mathrm{mmol}), 2$-amino-5amidiniumbenzenethiolate $2 \mathrm{a}(0.084 \mathrm{~g}, 0.5 \mathrm{mmol})$ and crystallization from $0.1 \mathrm{M}$ hydrochloric acid was obtained $0.098 \mathrm{~g}(58.3 \%)$ of colourless solid, m.p. $=289-293{ }^{\circ} \mathrm{C} ;{ }^{1} \mathrm{H}$

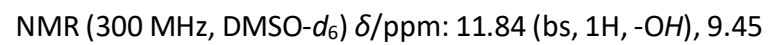
$\left(\mathrm{s}, 2 \mathrm{H},-\mathrm{C}\left(\mathrm{NH}_{2}\right)_{2}{ }^{+}\right), 9.17\left(\mathrm{~s}, 2 \mathrm{H},-\mathrm{C}\left(\mathrm{NH}_{2}\right)_{2}{ }^{+}\right), 8.62(\mathrm{~d}, 1 \mathrm{H}, J=1.6$ $\mathrm{Hz}, \operatorname{Ar}-H), 8.22(\mathrm{~d}, 1 \mathrm{H}, J=8.8 \mathrm{~Hz}, \mathrm{Ar}-H), 8.16(\mathrm{~d}, 1 \mathrm{H}, J=8.6$ $\mathrm{Hz}, \mathrm{Ar}-H$ ), 7.90 (dd, $1 \mathrm{H}, J=8.6 \mathrm{~Hz}, J=1.9 \mathrm{~Hz}, \mathrm{Ar}-H), 6.70$ (d, $1 \mathrm{H}, J=2.3 \mathrm{~Hz}, \mathrm{Ar}-H), 6.66(\mathrm{dd}, 1 \mathrm{H}, J=8.9 \mathrm{~Hz}, J=2.4 \mathrm{~Hz}$, Ar$H), 3.83\left(\mathrm{~s}, 3 \mathrm{H},-\mathrm{OCH}_{3}\right) ;{ }^{13} \mathrm{CNMR}\left(75 \mathrm{MHz}, \mathrm{DMSO}-d_{6}\right) \delta / \mathrm{ppm}$ : $168.3,165.5,163.3,158.5,154.9,134.6,130.0,125.9$, 123.4, 122.7, 121.6, 111.9, 107.2, 101.1, 55.4; LC-MS (ESI) $\mathrm{m} / \mathrm{z}: 300.1\left[\left(\mathrm{M}-\mathrm{Cl}^{-}\right)^{+}\right]$.

\section{6-Amidinium-2-(2,3,4-trihydroxyphenyl)benzothiazole chloride 6}

Using above described method from 2,3,4-trihydroxybenzaldehyde $1 \mathrm{~d}(0.077 \mathrm{~g}, 0.5 \mathrm{mmol}), 2$-amino-5-amidiniumbenzenethiolate $2 \mathrm{a}(0.084 \mathrm{~g}, 0.5 \mathrm{mmol})$ and crystallization from $0.1 \mathrm{M}$ hydrochloric acid was obtained $0.062 \mathrm{~g}(36.7 \%)$ of colourless solid, m.p. $>300^{\circ} \mathrm{C} ;{ }^{1} \mathrm{H}$ NMR (300 MHz, DMSO$\left.d_{6}\right) \delta / p p m: 10.92$ (bs, $\left.1 \mathrm{H},-\mathrm{OH}\right), 10.07$ (bs, $\left.1 \mathrm{H},-\mathrm{OH}\right), 9.46$ (s, $\left.2 \mathrm{H},-\mathrm{C}\left(\mathrm{NH}_{2}\right)_{2}{ }^{+}\right), 9.23\left(\mathrm{~s}, 2 \mathrm{H},-\mathrm{C}\left(\mathrm{NH}_{2}\right)_{2}{ }^{+}\right), 8.95$ (bs, $\left.1 \mathrm{H},-\mathrm{OH}\right)$, $8.62(\mathrm{~s}, 1 \mathrm{H}, \mathrm{Ar}-H), 8.14(\mathrm{~d}, 1 \mathrm{H}, J=8.5 \mathrm{~Hz}, \mathrm{Ar}-H), 7.90(\mathrm{~d}, 1 \mathrm{H}$, $J=8.5 \mathrm{~Hz}, \operatorname{Ar}-H), 7.61(\mathrm{~d}, 1 \mathrm{H}, J=8.8 \mathrm{~Hz}, \operatorname{Ar}-H), 6.57(\mathrm{~d}, 1 \mathrm{H}, J$ $=8.8 \mathrm{~Hz}, \mathrm{Ar}-H) ;{ }^{13} \mathrm{C}$ NMR (151 MHz, DMSO- $\left.d_{6}\right) \delta / \mathrm{ppm}$ : $169.8,165.5,154.9,150.1,147.2,134.1,133.0,125.9$, 123.4, 122.7, 121.4, 119.5, 111.2, 108.7; LC-MS (ESI) $\mathrm{m} / \mathrm{z}$ : $302.1\left[\left(\mathrm{M}-\mathrm{Cl}^{-}\right)^{+}\right]$.

6-(4,5-Dihydro-1H-imidazol-3-ium-2-yl)-2-(2-hydroxyphenyl) benzothiazole chloride 7

Using above described method from 2-hydroxybenzaldehyde 1a $(0.061 \mathrm{~g}, 0.5 \mathrm{mmol}), 2$-amino-5-(4,5-dihydro$1 \mathrm{H}$-imidazol-3-ium-2-yl)benzenethiolate hydrate $\mathbf{2 b}(0.5$ $\mathrm{mmol}$ ) and crystallization from $0.1 \mathrm{M}$ hydrochloric acid was obtained $0.103 \mathrm{~g}$ (62.1 \%) of colourless solid, m.p. 299-304 ${ }^{\circ} \mathrm{C}$; ${ }^{1 \mathrm{H} N M R}$ (300 MHz, DMSO- $d_{6}$ ) $\delta / \mathrm{ppm}: 11.72(\mathrm{~s}, 1 \mathrm{H},-\mathrm{OH})$, $10.86\left(\mathrm{~s}, 2 \mathrm{H},-\mathrm{C}(\mathrm{NH}-)_{2}{ }^{+}\right), 8.90(\mathrm{~s}, 1 \mathrm{H}, \mathrm{Ar}-\mathrm{H}), 8.34(\mathrm{~d}, 1 \mathrm{H}, J=$ $6.9 \mathrm{~Hz}, \operatorname{Ar}-H), 8.25(\mathrm{~d}, 1 \mathrm{H}, J=8.6 \mathrm{~Hz}, \operatorname{Ar}-H), 8.13(\mathrm{~d}, 1 \mathrm{H}, J=$ $8.5 \mathrm{~Hz}, \mathrm{Ar}-\mathrm{H}), 7.47(\mathrm{~m}, 1 \mathrm{H}, \mathrm{Ar}-\mathrm{H}), 7.21(\mathrm{~d}, 1 \mathrm{H}, J=8.2 \mathrm{~Hz}, \mathrm{Ar}-$ H), 7.05 (m, $1 \mathrm{H}, \mathrm{Ar}-\mathrm{H}), 4.04\left(\mathrm{~s}, 4 \mathrm{H},-\mathrm{CH}_{2} \mathrm{CH}_{2^{-}}\right) ;{ }^{13} \mathrm{C}$ NMR (75 $\left.\mathrm{MHz}, \mathrm{DMSO}-d_{6}\right) \delta / \mathrm{ppm}: 168.3,164.6,156.8,155.0,135.5$, $133.2,128.6,126.3,123.5,122.5,119.7,118.6,118.0$, 117.0, 44.4; LC-MS (ESI) m/z: 296.1 [(M-Cl-) $)^{+}$.

6-(4,5-Dihydro-1H-imidazol-3-ium-2-yl)-2-(2,4-dihydroxy phenyl)benzothiazole chloride 8

Using above described method from 2,4-dihydroxybenzaldehyde 1b (0.069 g, $0.5 \mathrm{mmol}), 2$-amino-5-(4,5dihydro- $1 \mathrm{H}$-imidazol-3-ium-2-yl)benzenethiolate hydrate 2b $(0.5 \mathrm{mmol})$ and crystallization from $0.1 \mathrm{M}$ hydrochloric acid was obtained $0.101 \mathrm{~g}(58.4 \%)$ of beige solid, m.p. $>300$ ${ }^{\circ} \mathrm{C} ;{ }^{1} \mathrm{H}$ NMR (600 MHz, DMSO- $d_{6}$ ) $\delta / p p m: 11.58(\mathrm{~s}, 1 \mathrm{H},-\mathrm{OH})$, $10.69\left(\mathrm{~s}, 2 \mathrm{H},-\mathrm{C}(\mathrm{NH}-)_{2}{ }^{+}\right), 10.36(\mathrm{~s}, 1 \mathrm{H},-\mathrm{OH}), 8.76(\mathrm{~d}, 1 \mathrm{H}, \mathrm{J}=$ $1.7 \mathrm{~Hz}, \mathrm{Ar}-H), 8.16-8.13(\mathrm{~m}, 2 \mathrm{H}, \mathrm{Ar}-\mathrm{H}), 8.04(\mathrm{dd}, 1 \mathrm{H}, J=8.6$ $\mathrm{Hz}, J=1.9 \mathrm{~Hz}, \mathrm{Ar}-H), 6.58(\mathrm{~d}, 1 \mathrm{H}, J=2.3 \mathrm{~Hz}, \mathrm{Ar}-\mathrm{H}), 6.49$ (dd, $1 \mathrm{H}, J=8.8 \mathrm{~Hz}, J=2.3 \mathrm{~Hz}, \mathrm{Ar}-\mathrm{H}), 4.04\left(\mathrm{~s}, 4 \mathrm{H},-\mathrm{CH}_{2} \mathrm{CH}_{2}-\right) ;{ }^{13} \mathrm{C}$ NMR (151 MHz, DMSO- $d_{6}$ ) $\delta / \mathrm{ppm}: 169.0,164.6,162.4$, $158.6,155.3,134.7,130.2,126.1,123.1,121.6,117.1$, 110.6, 108.7, 102.6, 44.3; LC-MS (ESI) m/z: 312.1 [(M-Cl-)+].

6-(4,5-Dihydro-1H-imidazol-3-ium-2-yl)-2-(2-hydroxy-4methoxyphenyl) benzothiazole chloride 9

Using above described method from 2-hydroxy-4methoxybenzaldehide $1 \mathrm{c}(0.076 \mathrm{~g}, 0.5 \mathrm{mmol}), 2$-amino-5(4,5 - dihydro - $1 \mathrm{H}$ - imidazol - 3 - ium - 2 - yl)benzenethiolate hydrate $2 \mathrm{~b}(0.5 \mathrm{mmol})$ and crystallization from $0.1 \mathrm{M}$ hydrochloric acid/acetone mixture was obtained $0.089 \mathrm{~g}$ (52.6\%) of pale yellow solid m.p. $291-296{ }^{\circ} \mathrm{C} ;{ }^{1} \mathrm{H}$ NMR (300 $\left.\mathrm{MHz}, \mathrm{DMSO}-d_{6}\right) \delta / \mathrm{ppm}: 10.99$ (bs, $3 \mathrm{H},-\mathrm{OH}+-\mathrm{C}(\mathrm{NH}-)_{2}{ }^{+}$), $8.81(\mathrm{~s}, 1 \mathrm{H}, \mathrm{Ar}-H), 8.24(\mathrm{~d}, 1 \mathrm{H}, J=8.9 \mathrm{~Hz}, \operatorname{Ar}-H), 8.18(\mathrm{~d}, 1 \mathrm{H}$, $J=8.6 \mathrm{~Hz}, \operatorname{Ar}-H), 8.08(\mathrm{~d}, 1 \mathrm{H}, J=8.6 \mathrm{~Hz}, \operatorname{Ar}-H), 6.71(\mathrm{~s}, 1 \mathrm{H}$, $\operatorname{Ar}-\mathrm{H}), 6.66(\mathrm{~d}, 1 \mathrm{H}, J=8.9 \mathrm{~Hz}, \mathrm{Ar}-\mathrm{H}), 4.04\left(\mathrm{~s}, 4 \mathrm{H},-\mathrm{CH}_{2} \mathrm{CH}_{2}-\right.$ ), $3.82\left(\mathrm{~s}, 3 \mathrm{H},-\mathrm{OCH}_{3}\right) ;{ }^{13} \mathrm{C} \mathrm{NMR}\left(75 \mathrm{MHz}\right.$, DMSO- $\left.d_{6}\right) \delta / \mathrm{ppm}$ : 
$168.7,164.6,163.4,158.5,155.1,134.7,123.0,126.1$, 123.1, 121.8, 117.4, 111.8, 107.1, 101.1, 55.3, 44.3; LC-MS

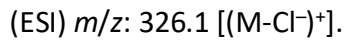

\section{6-(4,5-Dihydro-1H-imidazol-3-ium-2-yl)-2-(2,3,4-} trihydroxyphenyl)benzothiazole chloride 10

Using above described method from 2,3,4-trihydroxybenzaldehyde 1d $(0.077 \mathrm{~g}, 0.5 \mathrm{mmol}), 2$-amino-5-(4,5dihydro- $1 \mathrm{H}$-imidazol-3-ium-2-yl)benzenethiolate hydrate $\mathbf{2 b}(0.5 \mathrm{mmol})$ and crystallization from $0.1 \mathrm{M}$ hydrochloric acid was obtained $0.083 \mathrm{~g}$ (45.6\%) of beige solid, m.p. > 300 ${ }^{\circ} \mathrm{C} ;{ }^{1} \mathrm{H}$ NMR (300 MHz, DMSO- $d_{6}$ ) $\delta / \mathrm{ppm}$ : 10.89 (bs, $1 \mathrm{H}$, $\mathrm{OH}), 10.70$ (bs, 2H, $\left.-\mathrm{C}(\mathrm{NH}-)_{2}{ }^{+}\right), 10.11$ (bs, $\left.1 \mathrm{H},-\mathrm{OH}\right), 8.92$ (bs, $1 \mathrm{H},-\mathrm{OH}), 8.76(\mathrm{~d}, 1 \mathrm{H}, J=1.4 \mathrm{~Hz}, \mathrm{Ar}-\mathrm{H}), 8.16(\mathrm{~d}, 1 \mathrm{H}, J=8.6$ $\mathrm{Hz}, \mathrm{Ar}-H), 8.04(\mathrm{dd}, 1 \mathrm{H}, J=8.6 \mathrm{~Hz}, J=1.7 \mathrm{~Hz}, \mathrm{Ar}-H), 7.63(\mathrm{~d}$, $1 \mathrm{H}, J=8.8 \mathrm{~Hz}, \operatorname{Ar}-H), 6.57(\mathrm{~d}, 1 \mathrm{H}, J=8.8 \mathrm{~Hz}, \operatorname{Ar}-H), 4.04(\mathrm{~s}$, $\left.4 \mathrm{H},-\mathrm{CH}_{2} \mathrm{CH}_{2}-\right) ;{ }^{13} \mathrm{C}$ NMR (75 MHz, DMSO- $d_{6}$ ) $\delta /$ ppm: 170.0, $164.6,155.2,150.2,147.3,134.4,133.0,126.2,123.1$, 121.6, 119.5, 117.3, 111.3, 108.7, 44.3; LC-MS (ESI) $\mathrm{m} / \mathrm{z}$ : $328.1\left[\left(\mathrm{M}-\mathrm{Cl}^{-}\right)^{+}\right]$.

\section{General method for the synthesis of benzimidazole derivatives 12-19}

A mixture of equimolar amounts of corresponding aldehyde 1a-1d and 4-amidinium-1,2-phenylenediamine 11a or 2-(3,4-diaminophenyl)-4,5-dihydro- $1 \mathrm{H}$-imidazol-3ium chloride $\mathbf{1 1 b}$ in absolute ethanol with $p$-benzoquinone was stirred at reflux for 4 hours. The crude product was then filtered off, washed with diethyl ether and crystallized from ethanol to obtain pure compounds 12-19.

\section{5(6)-Amidinium-2-(2-hydroxyphenyl)benzimidazole} chloride 12

Using above described method from 2-hydroxybenzaldehyde 1a (0.100 g, $0.8 \mathrm{mmol}), 4$-amidinium-1,2phenylenediamine 11a $(0.153 \mathrm{~g}, 0.8 \mathrm{mmol})$ and $p$ benzoquinone $(0.089 \mathrm{~g}, 0.8 \mathrm{mmol})$ in absolute ethanol (3 $\mathrm{mL}$ ) was obtained $0.043 \mathrm{~g}(18.2 \%)$ of colourless solid; m.p. $>300{ }^{\circ} \mathrm{C} ;{ }^{1} \mathrm{H}$ NMR (300 MHz, DMSO- $\left.d_{6}\right) \delta / p p m: 13.62$ (bs, $1 \mathrm{H},-\mathrm{OH}), 12.83$ (bs, $1 \mathrm{H}, \mathrm{Bim}-\mathrm{NH}), 9.36\left(\mathrm{~s}, 2 \mathrm{H},-\mathrm{C}\left(\mathrm{NH}_{2}\right)_{2}{ }^{+}\right)$, $9.02\left(\mathrm{~s}, 2 \mathrm{H},-\mathrm{C}\left(\mathrm{NH}_{2}\right)_{2}{ }^{+}\right), 8.23-8.20(\mathrm{~m}, 2 \mathrm{H}, \mathrm{Ar}-\mathrm{H}), 7.87(\mathrm{~d}, 1 \mathrm{H}$ $J=8.5 \mathrm{~Hz}, \operatorname{Ar}-H), 7.74(\mathrm{dd}, 1 \mathrm{H}, J=8.5 \mathrm{~Hz}, J=1.5 \mathrm{~Hz}, \mathrm{Ar}-H)$, 7.48-7.43 (m, 1H, Ar-H), 7.12-7.04 (m, 2H, Ar-H); ${ }^{13} \mathrm{C} \mathrm{NMR}$ (75 MHz, DMSO- $d_{6}$ ) $\delta / p p m: 166.4,158.4,133.4,128.1$, 123.4, 120.0 (2C), 117.8 (2C); LC-MS (ESI) m/z: 253.1 [(M$\left.\left(\mathrm{Cl}^{-}\right)^{+}\right]$.

5(6)-Amidinium-2-(2,4-dihydroxyphenyl)benzimidazole chloride 13

Using above described method from 2,4-dihydroxybenzaldehyde 1b $(0.100 \mathrm{~g}, 0.7 \mathrm{mmol}), 4$-amidinium-1,2phenylenediamine 11a $(0.135 \mathrm{~g}, 0.7 \mathrm{mmol})$ and $p$ benzoquinone $(0.078 \mathrm{~g}, 0.7 \mathrm{mmol})$ in absolute ethanol (3.5
$\mathrm{mL}$ ) was obtained $0.023 \mathrm{~g}$ (10.4 \%) of violet solid; m.p. > 300 ${ }^{\circ} \mathrm{C} ;{ }^{1} \mathrm{H}$ NMR (300 MHz, DMSO- $d_{6}$ ) $\delta / \mathrm{ppm}: 13.46$ (bs, $1 \mathrm{H},-$ $\mathrm{OH}$ ), 12.73 (bs, $1 \mathrm{H}, \mathrm{Bim}-\mathrm{NH}$ ), 10.16 (bs, $1 \mathrm{H},-\mathrm{OH}$ ), 9.30 (bs, $\left.2 \mathrm{H},-\mathrm{C}\left(\mathrm{NH}_{2}\right)_{2}{ }^{+}\right), 8.99$ (bs, $\left.2 \mathrm{H},-\mathrm{C}\left(\mathrm{NH}_{2}\right)_{2}{ }^{+}\right), 8.12$ (bs, $\left.1 \mathrm{H}, \mathrm{Ar}-\mathrm{H}\right)$, $7.99(\mathrm{~d}, 1 \mathrm{H}, J=8.5 \mathrm{~Hz}, \mathrm{Ar}-H), 7.77(\mathrm{~d}, 1 \mathrm{H}, J=7.7 \mathrm{~Hz}, \mathrm{Ar}-\mathrm{H})$, $7.68(\mathrm{~d}, 1 \mathrm{H}, J=8.6 \mathrm{~Hz}, \mathrm{Ar}-H), 6.49(\mathrm{dd}, 1 \mathrm{H}, J=8.5 \mathrm{~Hz}, J=2.2$ $\mathrm{Hz}, \mathrm{Ar}-H), 6.45(\mathrm{~d}, 1 \mathrm{H}, J=2.1 \mathrm{~Hz}, \mathrm{Ar}-H) ;{ }^{13} \mathrm{C}$ NMR $(75 \mathrm{MHz}$, DMSO- $\left.d_{6}\right) \delta / p p m: 166.0,165.9,161.7,161.5,160.1,159.9$, $155.5,154.8,145.0,140.8,137.2,133.0,128.6,128.4$ $122.3,122.0,121.4,121.3,117.8,117.5,111.7,111.6,108.0$ (2C), 104.1, 104.0, 103.0 (2C); LC-MS (ESI) m/z: 269.1 [(M$\left(\mathrm{Cl}^{-}\right)^{+}$.

\section{5(6)-Amidinium-2-(2-hydroxy-4-} methoxyphenyl)benzimidazole chloride 14

Using above described method from 2-hydroxy-4methoxybenzaldehide 1c $(0.057 \mathrm{~g}, 0.4 \mathrm{mmol})$, 4amidinium-1,2-phenylenediamine 11a (0.070 g, $0.4 \mathrm{mmol})$ and $p$-benzoquinone $(0.041 \mathrm{~g}, 0.4 \mathrm{mmol})$ in absolute ethanol $(5 \mathrm{~mL})$ was obtained $0.058 \mathrm{~g}(48.5 \%)$ of dark grey solid; m.p. > $300{ }^{\circ} \mathrm{C} ;{ }^{1} \mathrm{H}$ NMR $\left(600 \mathrm{MHz}\right.$, DMSO- $\left.d_{6}\right) \delta / \mathrm{ppm}$ : $13.93(\mathrm{~s}, 1 \mathrm{H},-\mathrm{OH}), 13.87(\mathrm{~s}, 1 \mathrm{H},-\mathrm{OH}), 13.01(\mathrm{~s}, 1 \mathrm{H}, \mathrm{Bim}-\mathrm{NH})$, $12.93(\mathrm{~s}, 1 \mathrm{H}, \mathrm{Bim}-\mathrm{NH}), 9.44\left(\mathrm{~s}, 2 \mathrm{H},-\mathrm{C}\left(\mathrm{NH}_{2}\right)_{2}{ }^{+}\right), 9.37(\mathrm{~s}, 2 \mathrm{H}$, $\left.\mathrm{C}\left(\mathrm{NH}_{2}\right)_{2}{ }^{+}\right), 9.15\left(\mathrm{~s}, 4 \mathrm{H},-\mathrm{C}\left(\mathrm{NH}_{2}\right)_{2}{ }^{+}\right), 8.25-8.07(\mathrm{~m}, 4 \mathrm{H}, \mathrm{Ar}-\mathrm{H})$, $7.88-7.67(\mathrm{~m}, 4 \mathrm{H}, \mathrm{Ar}-\mathrm{H}), 6.66(\mathrm{dd}, 2 \mathrm{H}, J=8.8, J=2.4 \mathrm{~Hz}$, Ar$H), 6.64(\mathrm{~d}, 2 \mathrm{H}, J=2.3 \mathrm{~Hz}, \mathrm{Ar}-\mathrm{H}), 3.82\left(\mathrm{~s}, 6 \mathrm{H},-\mathrm{OCH}_{3}\right) ;{ }^{13} \mathrm{C}$ NMR $\left(75 \mathrm{MHz}\right.$, DMSO- $\left.d_{6}\right) \delta / \mathrm{ppm}: 166.5,163.3,160.5$, $128.8,122.9,107.4$ (2C), 105.8, 102.0 (2C), 55.9; LC-MS (ESI) $\mathrm{m} / \mathrm{z}: 283.2\left[\left(\mathrm{M}-\mathrm{Cl}^{-}\right)^{+}\right]$.

\section{5(6)-Amidinium-(2,3,4-trihydroxyphenyl)benzimidazole chloride 15}

Using above described method from 2,3,4-trihydroxybenzaldehyde 1d (0.100 g, $0.7 \mathrm{mmol}), 4$-amidinium-1,2phenylenediamine 11a $(0.121 \mathrm{~g}, 0.7 \mathrm{mmol})$ and $p$ benzoquinone $(0.070 \mathrm{~g}, 0.7 \mathrm{mmol})$ in absolute ethanol (3 $\mathrm{mL}$ ) was obtained $0.017 \mathrm{~g}(8.2 \%)$ of light brown solid; m.p.

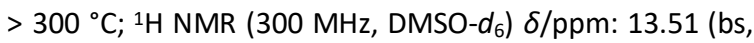
$1 \mathrm{H},-\mathrm{OH}), 12.88$ (bs, 1H, Bim-NH), 9.66 (bs, 1H, $-\mathrm{OH}), 9.33$ $\left(\mathrm{s}, 2 \mathrm{H},-\mathrm{C}\left(\mathrm{NH}_{2}\right)_{2}{ }^{+}\right), 8.99\left(\mathrm{~s}, 2 \mathrm{H},-\mathrm{C}\left(\mathrm{NH}_{2}\right)_{2}{ }^{+}\right), 8.58(\mathrm{bs}, 1 \mathrm{H},-\mathrm{OH})$, 8.14 (bs, $1 \mathrm{H}, \mathrm{Ar}-H), 7.81-7.78(\mathrm{~m}, 1 \mathrm{H}, \mathrm{Ar}-H), 7.72-7.69$ (m, $1 \mathrm{H}, \operatorname{Ar}-H), 7.51(\mathrm{~d}, 1 \mathrm{H}, J=8.6 \mathrm{~Hz}, \operatorname{Ar}-H), 6.53(\mathrm{~d}, 1 \mathrm{H}, J=8.7$ $\mathrm{Hz}, \mathrm{Ar}-H) ;{ }^{13} \mathrm{C}$ NMR $\left(75 \mathrm{MHz}, \mathrm{DMSO}-d_{6}\right) \delta / \mathrm{ppm}: 166.4$, 149.9, 148.9, 133.7, 122.9, 122.0, 118.0, 108.4 (2C), 104.7; LC-MS (ESI) $\mathrm{m} / \mathrm{z}: 285.3\left[\left(\mathrm{M}-\mathrm{Cl}^{-}\right)^{+}\right]$.

\section{5(6)-(4,5-Dihydro-1H-imidazol-3-ium-2-yl)-2-(2-} hydroxyphenyl)benzimidazole chloride 16 Using above described method from 2-hydroxybenzaldehyde 1a (0.100 g, $0.9 \mathrm{mmol}), 2$-(3,4-diaminophenyl)4,5-dihydro- $1 H$-imidazol-3-ium chloride $11 \mathrm{~b}(0.17$ 4g, 0.9 $\mathrm{mmol}$ ) and $p$-benzoquinone $(0.089 \mathrm{~g}, 0.9 \mathrm{mmol})$ in absolute ethanol ( $3 \mathrm{~mL}$ ) was obtained $0.127 \mathrm{~g}(45.5 \%)$ of grey-violet 
solid; m.p. > $300{ }^{\circ} \mathrm{C} ;{ }^{1} \mathrm{H}$ NMR $\left(300 \mathrm{MHz}\right.$, DMSO- $\left.d_{6}\right) \delta / \mathrm{ppm}$ : 13.96 (bs, $1 \mathrm{H},-\mathrm{OH}), 12.62$ (bs, $1 \mathrm{H}, \mathrm{Bim}-\mathrm{NH}), 10.70$ (s, 2H, $\left.\mathrm{C}(\mathrm{NH}-)_{2}{ }^{+}\right), 8.42(\mathrm{~s}, 1 \mathrm{H}, \mathrm{Ar}-\mathrm{H}), 8.26(\mathrm{~d}, 1 \mathrm{H}, J=7.3 \mathrm{~Hz}, \mathrm{Ar}-\mathrm{H})$, $7.92(\mathrm{~d}, 1 \mathrm{H}, J=8.6 \mathrm{~Hz}, \mathrm{Ar}-H), 7.87(\mathrm{~d}, 1 \mathrm{H}, J=8.5 \mathrm{~Hz}, \mathrm{Ar}-H)$, 7.47-7.41 (m, 1H, Ar-H), 7.11-7.02 (m, 2H, Ar-H), 4.03 (s, $\left.4 \mathrm{H},-\mathrm{CH}_{2} \mathrm{CH}_{2}-\right) ;{ }^{13} \mathrm{CNMR}\left(150 \mathrm{MHz}\right.$, DMSO- $d_{6}$ ) $\delta / \mathrm{ppm}: 165.2$, $158.0,157.8,146.6,132.6,127.5,119.4(2 \mathrm{C}), 117.2(2 \mathrm{C})$, 115.6, 112.3, 107.7, 44.2 (2C); LC-MS (ESI) m/z: 279.2 [(M$\left.\left.\mathrm{Cl}^{-}\right)^{+}\right]$.

5(6)-(4,5-Dihydro-1H-imidazol-3-ium-2-yl)-2-(2,4dihydroxyphenyl)benzimidazole chloride 17

Using above described method from 2,4-dihydroxybenzaldehyde 1b $(0.080 \mathrm{~g}, 0.6 \mathrm{mmol}), 2$ 2-(3,4-diaminophenyl)-4,5-dihydro- $1 \mathrm{H}$-imidazol-3-ium chloride $\mathbf{1 1 b}$ $(0.123 \mathrm{~g}, 0.6 \mathrm{mmol})$ and $p$-benzoquinone $(0.063 \mathrm{~g}, 0.6$ $\mathrm{mmol}$ ) in absolute ethanol $(3.5 \mathrm{~mL})$ was obtained $0.035 \mathrm{~g}$ (18.2\%) of grey-violet solid; m.p. $>300{ }^{\circ} \mathrm{C}$; ${ }^{1} \mathrm{H}$ NMR (600 $\left.\mathrm{MHz}, \mathrm{DMSO}-d_{6}\right) \delta / \mathrm{ppm}: 13.70$ (bs, $\left.1 \mathrm{H},-\mathrm{OH}\right), 13.58$ (bs, $1 \mathrm{H}$, $-\mathrm{OH}), 12.75$ (s, 1H, Bim-NH), 12.58 (s, 1H, Bim-NH), 10.56 (bs, $\left.4 \mathrm{H},-\mathrm{C}(\mathrm{NH}-)_{2}{ }^{+}\right), 10.23(\mathrm{~s}, 1 \mathrm{H},-\mathrm{OH}), 10.21(\mathrm{~s}, 1 \mathrm{H},-\mathrm{OH})$, $8.35(\mathrm{~s}, 1 \mathrm{H}, \operatorname{Ar}-H), 8.24(\mathrm{~s}, 1 \mathrm{H}, \mathrm{Ar}-H), 8.06(\mathrm{~d}, 1 \mathrm{H}, J=8.3 \mathrm{~Hz}$, $\operatorname{Ar}-H), 7.99(\mathrm{~d}, 1 \mathrm{H}, J=7.1 \mathrm{~Hz}, \mathrm{Ar}-H), 7.85-7.82(\mathrm{~m}, 3 \mathrm{H}, \mathrm{Ar}-$ H), $7.77(\mathrm{~d}, 1 \mathrm{H}, J=7.2 \mathrm{~Hz}, \mathrm{Ar}-\mathrm{H}), 6.49(\mathrm{~d}, 2 \mathrm{H}, J=8.6 \mathrm{~Hz}, \mathrm{Ar}-$ H), 6.45 (s, 2H, Ar-H), $4.02\left(\mathrm{~s}, 8 \mathrm{H},-\mathrm{CH}_{2} \mathrm{CH}_{2}-\right) ;{ }^{13} \mathrm{C}$ NMR (75 $\left.\mathrm{MHz}, \mathrm{DMSO}-d_{6}\right) \delta / \mathrm{ppm}: 165.8,162.2,160.4,129.1,123.1$, 115.9, 108.5 (2C), 104.5, 103.5 (2C), 44.7 (2C); LC-MS (ESI) $\mathrm{m} / \mathrm{z}: 298.2\left[\left(\mathrm{M}-\mathrm{Cl}^{-}\right)^{+}\right]$.

5(6)-(4,5-Dihydro-1H-imidazol-3-ium-2-yl)-2-(2-hydroxy-4methoxyphenyl)benzimidazole chloride 18

Using above described method from 2-hydroxy-4methoxybenzaldehide 1c $(0.071 \mathrm{~g}, 0.5 \mathrm{mmol}), 2-(3,4-$ diaminophenyl)-4,5-dihydro- $1 \mathrm{H}$-imidazol-3-ium chloride 11b $(0.100 \mathrm{~g}, 0.5 \mathrm{mmol})$ and $p$-benzoquinone $(0.051 \mathrm{~g}, 0.5$ $\mathrm{mmol})$ in absolute ethanol $(5 \mathrm{~mL})$ was obtained $0.103 \mathrm{~g}$ (63.6\%) of dark grey solid; m.p. > $300^{\circ} \mathrm{C} ;{ }^{1} \mathrm{H}$ NMR $(600 \mathrm{MHz}$, DMSO- $d_{6}$ ) $\delta / p p m: ~ 13.89$ (bs, $\left.1 \mathrm{H},-\mathrm{OH}\right), 12.82$ (bs, $1 \mathrm{H}, \mathrm{Bim}-$ $\mathrm{NH}$ ), 10.72 (bs, $\left.2 \mathrm{H},-\mathrm{C}(\mathrm{NH}-)_{2}{ }^{+}\right), 8.37$ (bs, $\left.1 \mathrm{H}, \mathrm{Ar}-\mathrm{H}\right), 8.18$ (bs, $1 \mathrm{H}, \operatorname{Ar}-H), 7.89(\mathrm{~s}, 1 \mathrm{H}, \mathrm{Ar}-H), 7.82(\mathrm{~s}, 1 \mathrm{H}, \mathrm{Ar}-H), 6.66$ (dd, $1 \mathrm{H}$, $J=8.7, J=2.3 \mathrm{~Hz}, \operatorname{Ar}-H), 6.63(\mathrm{~d}, 1 \mathrm{H}, J=2.3 \mathrm{~Hz}, \operatorname{Ar}-H), 4.02$ (s, $\left.4 \mathrm{H},-\mathrm{CH}_{2} \mathrm{CH}_{2}-\right), 3.83\left(\mathrm{~s}, 3 \mathrm{H},-\mathrm{OCH}_{3}\right) ;{ }^{13} \mathrm{C} \mathrm{NMR}(75 \mathrm{MHz}$, DMSO- $\left.d_{6}\right) \delta / p p m: 165.8,163.4,128.9,123.2,116.0,107.4$ (2C), 105.8, 102.0 (2C), 55.9, 44.7 (2C); LC-MS (ESI) $\mathrm{m} / \mathrm{z}$ : $309.2\left[\left(\mathrm{M}-\mathrm{Cl}^{-}\right)^{+}\right]$.

5(6)-(4,5-Dihydro-1H-imidazol-3-ium-2-yl)-2-(2,3,4trihydroxyphenyl)benzimidazole chloride 19

Using above described method from 2,3,4-trihydroxybenzaldehyde 1d (0.100 g, $0.7 \mathrm{mmol}), 2$-(3,4-diaminophenyl)4,5-dihydro- $1 \mathrm{H}$-imidazol-3-ium chloride $11 \mathrm{~b}$ (0.138 g, 0.7 $\mathrm{mmol}$ ) and $p$-benzoquinone $(0.070 \mathrm{~g}, 0.7 \mathrm{mmol})$ in absolute ethanol $(3 \mathrm{~mL})$ was obtained $0.050 \mathrm{~g}(22.2 \%)$ of brown solid; m.p. > $300{ }^{\circ} \mathrm{C} ;{ }^{1} \mathrm{H}$ NMR (300 MHz, DMSO- $\left.d_{6}\right) \delta /$ ppm: 13.51 (bs, 1H, $-\mathrm{OH}$ ), 11.19 (bs, $\left.2 \mathrm{H},-\mathrm{C}(\mathrm{NH}-)_{2}{ }^{+}\right), 10.73$ (bs, $1 \mathrm{H}$, $-\mathrm{OH}), 10.61(\mathrm{~s}, 1 \mathrm{H},-\mathrm{OH}), 9.11-9.08(\mathrm{~m}, 1 \mathrm{H}, \mathrm{Ar}-\mathrm{H}), 8.54(\mathrm{~d}$, $1 \mathrm{H}, J=8.8 \mathrm{~Hz}, \mathrm{Ar}-\mathrm{H}), 8.46-8.40(\mathrm{~m}, 1 \mathrm{H}, \mathrm{Ar}-\mathrm{H}), 7.94$ (bs, $1 \mathrm{H}$, $\operatorname{Ar}-H), 7.52(\mathrm{~d}, 1 \mathrm{H}, J=7.7 \mathrm{~Hz}, \mathrm{Ar}-\mathrm{H}), 4.14\left(\mathrm{~s}, 4 \mathrm{H},-\mathrm{CH}_{2} \mathrm{CH}_{2}-\right.$ ), 4.05 (s, 4H, $-\mathrm{CH}_{2} \mathrm{CH}_{2}-$ ); LC-MS (ESI) m/z: $311.3\left[\left(\mathrm{M}-\mathrm{Cl}^{-}\right)^{+}\right]$.

\section{Antioxidative Activity}

Determination of the reducing activity of the stable radical 1,1-diphenyl-picrylhydrazyl (DPPH)

The determination of reducing activity of the stable DPPH radical was measured according to previously reported procedure with modification. ${ }^{[21]}$ Briefly, to solution of DPPH (final concentration $100 \mu \mathrm{M}$ ) in methanol was added equal volume of the tested compounds various concentrations dissolved in DMSO. The assay was carried out in a 96 well microtiter plate. Methanol and DMSO was used as control solution. Sample blank were also performed.

After 30 min in dark at room temperature the absorbance was recorded at $517 \mathrm{~nm}$ on microplate reader $\mu Q$ uant (Biotec Inc.). All measures were done in triplicate and averaged. The results were presented as $I_{50}$ in Table 1.

\section{Free radical scavenging ability by the use of a stable ABTS radical cation (2,2'-azinobis-(3-ethylbenzthiazoline-6- sulphonic acid)}

The total antioxidant activity assay was adjusted for microplate reader. ${ }^{[22]}$ For the standard ABTS assay, ABTS*+ was prepared by mixing an ABTS stock solution $(7 \mathrm{mM}$ in water) with $2.45 \mathrm{mM}$ potassium persulfate and left in dark at room temperature for $12-16 \mathrm{~h}$ until reaching a stable oxidative state. Before analysis, the ABTS*+ solution was diluted 100 times with methanol to obtain an absorbance of 0.700 (0.01 at $734 \mathrm{~nm}$ ). The radical was stable in this form for more than two days when stored in the dark at room temperature. Standards and solutions of tested compounds $(20 \mu \mathrm{L})$ were mixed with working $\mathrm{ABTS} \bullet+$ radical cation solution $(280 \mu \mathrm{L})$ to each well the microplate, shake and incubate at room temperature for $5 \mathrm{~min}$. The decrease of absorbance at $734 \mathrm{~nm}$ was recorded by microplate reader $\mu$ Quant (Biotec Inc.). Methanol (without $\mathrm{ABTS}^{\bullet+}$ solution) was used as a control and $\mathrm{BHT}$ as reference compound. All compounds were tested in triplicate and averaged. Results were expressed as $I C_{50}$ and presented in Table 1.

\section{Determination of Ferric Reducing/Antioxidant Power (FRAP assay)}

The FRAP method was adjusted for a 96-well microplate according to previously reported procedure. ${ }^{[23]}$ The antioxidant capacity of the tested compounds was estimated as their power to reduce the TPTZ-Fe(III) to TPTZ$\mathrm{Fe}$ (II) complex, which is fast, simple and reproducible. A 
Table 1. IC $C_{50}$ values of 2-arylbezimidazoles and benzothiazoles for DPPH and ABTS free radical scavenging activity*<smiles></smiles>

\begin{tabular}{|c|c|c|c|c|c|c|c|}
\hline \multirow{2}{*}{ Cpd } & \multirow{2}{*}{$\mathrm{R}_{1}$} & \multirow{2}{*}{$\mathrm{R}_{2}$} & \multirow{2}{*}{$\mathrm{R}_{3}$} & \multirow{2}{*}{$x$} & \multirow{2}{*}{$\mathrm{Am}$} & \multicolumn{2}{|c|}{ Scavenging activity $\left(\mathrm{IC}_{50} \mu \mathrm{M}\right)$} \\
\hline & & & & & & DPPH & ABTS \\
\hline 3 & $\mathrm{OH}$ & $\mathrm{H}$ & $\mathrm{H}$ & $S$ & unsubstituted & $>100$ & $>100$ \\
\hline 4 & $\mathrm{OH}$ & $\mathrm{H}$ & $\mathrm{OH}$ & S & unsubstituted & $>100$ & $13.34 \pm 0.8^{(b)}$ \\
\hline 5 & $\mathrm{OH}$ & $\mathrm{H}$ & $\mathrm{OCH}_{3}$ & S & unsubstituted & no & $>100$ \\
\hline 6 & $\mathrm{OH}$ & $\mathrm{OH}$ & $\mathrm{OH}$ & S & unsubstituted & $23.89 \pm 4.7^{(\mathrm{a})}$ & $7.64 \pm 1.5^{(b)}$ \\
\hline 7 & $\mathrm{OH}$ & $\mathrm{H}$ & $H$ & $S$ & 2-imidazolinyl & no & $>100$ \\
\hline 8 & $\mathrm{OH}$ & $\mathrm{H}$ & $\mathrm{OH}$ & S & 2-imidazolinyl & $>100$ & $9.83 \pm 0.9^{(b)}$ \\
\hline 9 & $\mathrm{OH}$ & $\mathrm{H}$ & $\mathrm{OCH}_{3}$ & S & 2-imidazolinyl & no & $>100$ \\
\hline 10 & $\mathrm{OH}$ & $\mathrm{OH}$ & $\mathrm{OH}$ & S & 2-imidazolinyl & $34.76 \pm 7.0^{(b)}$ & $9.33 \pm 0.7^{(b)}$ \\
\hline 12 & $\mathrm{OH}$ & $\mathrm{H}$ & $\mathrm{H}$ & $\mathrm{NH}$ & unsubstituted & no & no \\
\hline 13 & $\mathrm{OH}$ & $\mathrm{H}$ & $\mathrm{OH}$ & $\mathrm{NH}$ & unsubstituted & $>100$ & $10.74 \pm 0.5^{(b)}$ \\
\hline 14 & $\mathrm{OH}$ & $\mathrm{H}$ & $\mathrm{OCH}_{3}$ & $\mathrm{NH}$ & unsubstituted & $>100$ & $53.59 \pm 11.4^{(\text {b) }}$ \\
\hline 15 & $\mathrm{OH}$ & $\mathrm{OH}$ & $\mathrm{OH}$ & $\mathrm{NH}$ & unsubstituted & $23.57 \pm 2.7^{(\mathrm{a})}$ & $6.84 \pm 2.4^{(b)}$ \\
\hline 16 & $\mathrm{OH}$ & $\mathrm{H}$ & $\mathrm{H}$ & $\mathrm{NH}$ & 2-imidazolinyl & $>100$ & $>100$ \\
\hline 17 & $\mathrm{OH}$ & $\mathrm{H}$ & $\mathrm{OH}$ & $\mathrm{NH}$ & 2-imidazolinyl & no & $6.21 \pm 0.4^{(b)}$ \\
\hline 18 & $\mathrm{OH}$ & $\mathrm{H}$ & $\mathrm{OCH}_{3}$ & $\mathrm{NH}$ & 2-imidazolinyl & $>100$ & $35.69 \pm 1.3^{(b)}$ \\
\hline 19 & $\mathrm{OH}$ & $\mathrm{OH}$ & $\mathrm{OH}$ & $\mathrm{NH}$ & 2-imidazolinyl & $92.92 \pm 7.4^{(b)}$ & $32.04 \pm 3.7^{(\mathrm{a})}$ \\
\hline BHT & & & & & $\mathrm{H}$ & $25 \pm 4.2^{(\mathrm{a})}$ & $28.0 \pm 2.3^{(\mathrm{a})}$ \\
\hline
\end{tabular}

* Values are presented as means \pm standard deviation.

$a, b$ Values with different superscripts in the same column are significantly different $(P<0.05)$ by the t-test (compounds vs control BHT)

solution of $10 \mathrm{mM}$ TPTZ and $20 \mathrm{mM}$ ferric chloride was diluted in $300 \mathrm{mM}$ sodium acetate buffer $(\mathrm{pH} 3.6)$ at a ratio of 1:1:10. The tested compound solution $(20 \mu \mathrm{l})$ was added to the 96-well microplate followed by working FRAP solution $(280 \mu \mathrm{l})$. The mixture was shaken and incubated 30 $\min$ at $37{ }^{\circ} \mathrm{C}$ in the dark. Final concentration of tested compounds was $0.01 \mathrm{mM}$ for all except for compounds 6 , 10, 15 and $19(250 \mu \mathrm{M})$. The absorbance at $593 \mathrm{~nm}$ was recorder using microplate reader $\mu$ Quant (Biotec Inc.). For the standard curve construction ferrous sulphate $\left(\mathrm{FeSO}_{4} \mathrm{X}\right.$ $7 \mathrm{H}_{2} \mathrm{O}$ ) was used and range of standard curve was 20-2000 $\mu \mathrm{mol} / \mathrm{L}$. All results were then expressed as $\mathrm{Fe}^{2+}$ equivalents $\left(\mathrm{Fe}^{2+} \mu \mathrm{mol}\right)$. All compounds were tested in triplicate and the results were averaged and presented in Table 1.

\section{Statistical analysis}

Calculation of $\mathrm{IC}_{50}$ value is performed by using GraphPadPrism software (GraphPad Software, Inc. La Jolla, CA USA 2012). Briefly, individual concentration effect curves are generated by plotting the logarithm of the concentration of tested compounds $(X)$ against corresponding percent inhibition values $(Y)$ using least squares fit. All experiments were tested at least three times. Results were expressed as mean \pm standard deviation (SD) and analyzed using the Student's t-test to assess the statistical significance using the Statistica software (STATISTICA 2010 program, Tulsa, OK, USA). P values $<0.05$ were regarded as significant.

\section{RESULTS AND DISCUSSION}

\section{Chemistry}

The synthesis of 6-amidino-2-arylbenzothiazole derivatives (3-10) was carried out by condensation reaction (Scheme 1). Recently, we found glacial acetic acid to be an efficient solvent for direct condensation of aldehydes and amidino substituted 2-aminothiophenoles giving rise to the corresponding 2-substituted-6-amidinobenzothiazolyl compounds in high yield without the need of any catalyst or oxidant. [24] Consequently, cyclocondensation of 2amino-5-amidiniumbenzenethiolate $2 \mathrm{a}^{[19]}$ and 2-amino-5(4,5 - dihydro - $1 \mathrm{H}$ - imidazol - 3 - ium - 2 - yl)-benzenethiolate $\mathbf{2 b}^{[19]}$ with commercially available aldehydes $\mathbf{1 a}-\mathbf{1 d}$ in refluxing acetic acid followed by quenching with hydrochloric acid afforded targeted cationic 6-amidino-2arylbenzothiazole compounds which were isolated as hydrochloride salts. The zwitterionic precursor $\mathbf{2 a}$ and $\mathbf{2} \mathbf{b}$ were prepared by Pinner reaction from 6- 


$$
\begin{aligned}
& \text { (n) } \\
& \begin{array}{l}
\text { 1a } R_{1}=O H, R_{2}=R_{3}=H \\
\text { 1b } R_{1}=R_{3}=O H, R_{2}=H
\end{array} \quad \text { 2a Am }=-\mathrm{NH}_{2}^{N H} \\
& \begin{array}{l}
\text { 1c } R_{1}=O H, R_{2}=H, R_{3}=O_{3} \quad \text { 2b Am }=\longrightarrow-N \\
\text { 1d } R_{1}=R_{2}=R_{3}=O H
\end{array} \\
& \left.\begin{array}{ll}
4 R_{1}=R_{3}=O H, R_{2}=H \\
5 R_{1}=O H, R_{2}=H, R_{3}=O C H_{3} \\
6 R_{1}=R_{2}=R_{3}=O H
\end{array}\right\} A m={ }_{N}^{N H} \\
& \left.\begin{array}{ll}
7 \mathrm{R}_{1}=\mathrm{OH}, \mathrm{R}_{2}=\mathrm{R}_{3}=\mathrm{H} \\
8 \mathrm{R}_{1}=\mathrm{R}_{3}=\mathrm{OH}, \mathrm{R}_{2}=\mathrm{H} \\
9 \mathrm{R}_{1}=\mathrm{OH}, \mathrm{R}_{2}=\mathrm{H}, \mathrm{R}_{3}=\mathrm{OCH}_{3} \\
10 \mathrm{R}_{1}=\mathrm{R}_{2}=\mathrm{R}_{3}=\mathrm{OH}
\end{array}\right\} A m={ }_{H}^{N}
\end{aligned}
$$

Scheme 1.

cynobenzothiazole according to our previously developed method. ${ }^{[19]}$

Amidino and 2-imidazolinyl substituted benzimidazole derivatives $\mathbf{1 2 - 1 9}$ were obtained according to the experimental procedure shown in the Scheme 2 . Starting from previously prepared 4-amidino/4-(2imidazolinyl)-1,2-phenylenediamines hydrochlorides 11a and $11 b,[20]$ due to the cyclocondensation with corresponding benzaldehydes $\mathbf{1 a - 1 d}$ in absolute ethanol and by using with $p$-benzoquinone as oxidizing reagent, 2-phenylbenzimidazole derivatives bearing amidino substituents 12-19 were prepared as hydrochloride salts.

The structures of all newly prepared benzothiazole and benzimidazole derivatives were determined by using ${ }^{1} \mathrm{H}$ and ${ }^{13} \mathrm{C}$ NMR spectroscopy and mass spectrometry. NMR analysis based on the values of $\mathrm{H}-\mathrm{H}$ coupling constants and chemical shifts in the ${ }^{1} \mathrm{H}$ and ${ }^{13} \mathrm{C}$ NMR spectra confirmed the structures of compounds. Furthermore, IR spectroscopy was used for the monitoring of Pinner reaction due to the synthesis of main precursors $\mathbf{2 a}, \mathbf{2} \mathbf{b}, \mathbf{1 1} \mathbf{a}$ and $\mathbf{1 1} \mathbf{b}$.

\section{Antioxidative Activity}

In this research we have synthesized benzimidazole and benzothiazole derivatives which we envisioned to show protection against free radicals attack as an index of pharmacological usefulness. To determine antioxidant activity of different benzazoles, the reducing activity of the stable radical 1,1-diphenyl-picrylhydrazyl (DPPH), free radical scavenging ability by the use of radical cation 2,2azinobis-(3-ethylbenzthiazoline-6-sulphonic acid (ABTS) and ferric reducing/antioxidant power (FRAP) were evaluated. The evaluation was conducted by in vitro methods which require a spectrometric approach. [25]

The radical scavenging assay using stable radical DPPH indicates the ability of tested compounds to donate proton/electron. The DPPH final concentration was $100 \mu \mathrm{M}$ and results were read after $30 \mathrm{~min}$ and presented in Table 1. The results were expressed as $I C_{50}$ values with the exception of 5, 7, 9, 12 and 17 which did not exhibit activity under assay condition. Based on experimental results presented, among all synthesized compounds, benzo-

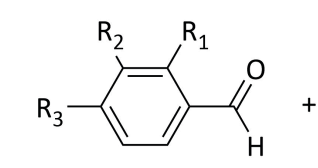

1a $\mathrm{R}_{1}=\mathrm{OH}, \mathrm{R}_{2}=\mathrm{R}_{3}=\mathrm{H}$

1b $\mathrm{R}_{1}=\mathrm{R}_{3}=\mathrm{OH}, \mathrm{R}_{2}=\mathrm{H}$

1c $\mathrm{R}_{1}=\mathrm{OH}, \mathrm{R}_{2}=\mathrm{H}, \mathrm{R}_{3}=\mathrm{OCH}_{3}$

1d $R_{1}=R_{2}=R_{3}=O H$

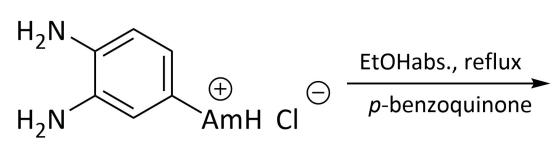

11a $\mathrm{Am}=$<smiles>CC(=N)N</smiles>

11b $A m={ }_{\mathrm{H}}^{\mathrm{N}}$<smiles>[R]c1ccc(-c2nc3ccc([TlH])cc3[nH]2)c([R])c1[R]</smiles>

$\left.\left.\begin{array}{l}12 \mathrm{R}_{1}=\mathrm{OH}, \mathrm{R}_{2}=\mathrm{R}_{3}=\mathrm{H} \\ 13 \mathrm{R}_{1}=\mathrm{R}_{3}=\mathrm{OH}, \mathrm{R}_{2}=\mathrm{H} \\ 14 \mathrm{R}_{1}=\mathrm{OH}, \mathrm{R}_{2}=\mathrm{H}, \mathrm{R}_{3}=\mathrm{OCH}_{3} \\ 15 \mathrm{R}_{1}=\mathrm{R}_{2}=\mathrm{R}_{3}=\mathrm{OH}\end{array}\right\} \mathrm{Am}=\mathrm{NH}_{16}^{\mathrm{NH}} \begin{array}{l}17 \mathrm{R}_{1}=\mathrm{OH}, \mathrm{R}_{2}=\mathrm{R}_{3}=\mathrm{H} \\ 18 \mathrm{R}_{1}=\mathrm{OH}, \mathrm{R}_{2}=\mathrm{H}, \mathrm{R}_{3}=\mathrm{OCH}_{3} \\ 19 \mathrm{R}_{1}=\mathrm{R}_{2}=\mathrm{R}_{3}=\mathrm{OH}\end{array}\right\} \mathrm{Am}=\mathrm{N}_{\mathrm{H}}^{\mathrm{N}}$

Scheme 2 . 
thiazole derivatives 6 and 10 and benzimidazole derivatives 15 and 19 exerted scavenging activity towards DPPH.

The most potent compounds $\mathbf{6}$ and $\mathbf{1 5}$ have exerted $\mathrm{IC}_{50}(23.9 \pm 4.7 \mu \mathrm{M} ; 23.6 \pm 2.7 \mu \mathrm{M}$, respectively) similar to control compound 2,6-bis(1,1-dimethylethyl)-4-methylphenol $(\mathrm{BHT})(25.0 \pm 4.2 \mu \mathrm{M})(\mathrm{P}>0.05)$. The compound 10 exhibited good antioxidant capacity $(34.8 \pm 7.0 \mu \mathrm{M})$ while compound 19 showed lower but still good radical scavenging activity $(92.9 \pm 7.4 \mu \mathrm{M})$. The compounds $\mathbf{3}, \mathbf{4}, \mathbf{8}$, 13, 14, 16 and 18 showed low antioxidant activity, values ranged from 5 to $1 \mathrm{mM}$. Regarding substitution pattern it was evident that with increasing the number of hydroxy groups attached on phenyl ring, the scavenging activity was improved.

Moreover, it was noticed that the type of the amidino group attached on the heteroaromatic scaffold also influenced the antioxidative activity. Thus, derivatives bearing the unsubstituted amidino group 6 and $\mathbf{1 5}$ showed higher activity in comparison to the derivatives with 2 imidazolinyl group $\mathbf{1 0}$ and $\mathbf{1 9}$. In addition, there were no any differences in the antioxidative activity between benzothiazole or benzimidazole derivatives substituted with amidino group 6 and 15. Furthermore, 2-imidazolinyl substituted benzothiazole derivative $\mathbf{1 0}$ compared to the same benzimidazole analogue 19 showed significantly higher antioxidative activity but lower than control BHT.

Following assay employed in the testing of antioxidant ability of benzazole derivatives was ABTS radical cation assay at $\mathrm{pH} 4$ as well. ${ }^{[26]}$ The ability of pure compounds to decrease the color reacting directly with $\mathrm{ABTS}^{*+}$ radical is a measure of their antioxidant capacity. In addition, $\mathrm{ABTS}^{\bullet+}$ radicals are more stable then $\mathrm{DPPH}$ radicals and could be used to evaluate hydrophilic and lipophilic compounds. ${ }^{[23]}$ The results are presented as $I C_{50}$ in Table 1.

Obtained results revealed a higher number of active compounds in comparison to the DPPH assay. The different number of hydroxy groups attached on the phenyl ring strongly influenced the antioxidative activity with the trihydroxy substituted derivatives being the most active ones. Trihydroxy substituted benzothiazole 6 and 10 and benzimidazole $\mathbf{1 5}$ and $\mathbf{1 9}$ derivatives showed similar activity pattern as in the DPPH assay with the 2-imidazolinyl substituted benzimidazole 19 showing the weakest activity. Moreover, derivatives bearing two hydroxyl groups 4, 8, 13 and 17 also showed good antioxidative activity. Thus, benzimidazole derivatives $\mathbf{1 3}$ and $\mathbf{1 7}$ exerted improved activity in comparison to the same benzothiazole analogues $\mathbf{4}$ and $\mathbf{8}$ with the compounds bearing 2-imidazolinyl group being more active. Due to the replacement of one hydroxy group with the methoxy group attached on the phenyl ring, antioxidative activity was decreased with the benzimidazole derivatives 14 and 18 showing more pronounced

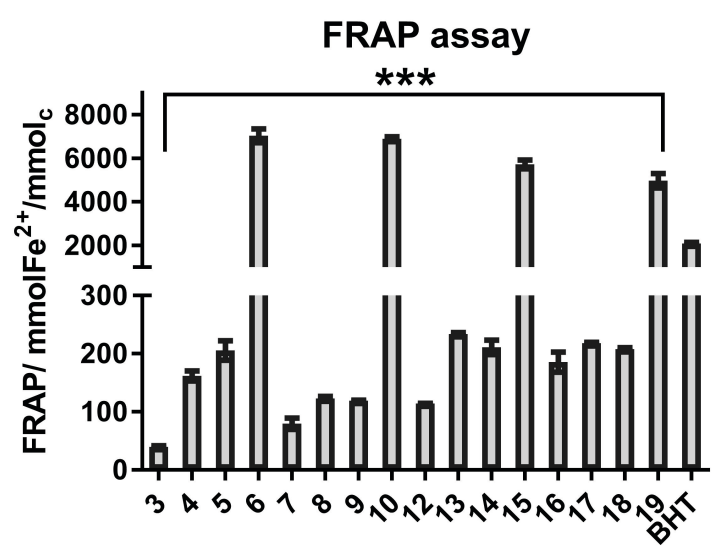

Figure 2. Reducing power of tested compounds measured as FRAP ( $P<0.01$ for all compounds vs BHT).

activity. The most active compounds 4, 6, 8, 10, 13, 15 and 17 which exhibited antioxidant activity higher then BHT ranging from 6.2 to $13.3 \mu \mathrm{M}(\mathrm{P}<0.05)$. The compounds 18 and 19 showed almost similar results as control compound $\mathrm{BHT}(35.7 \pm 1.3 \mu \mathrm{M}, 32.0 \pm 3.7 \mu \mathrm{M}$; respectively).

The reducing power of investigated compounds was determined by FRAP assay. This method is based on the ability of compounds to reduce ferric tripyridyl triazine complex (TPTZ) to ferrous ( $\mathrm{Fe}^{2+}$ ) form producing an intense blue colour as result.

The reaction progress is monitored by change in the absorbance at $593 \mathrm{~nm}$. Higher increase in the absorbance signifies higher reduction potential of investigated compounds. The FRAP assay results of tested compounds are presented in Figure 2.

Presented results revealed that only four derivatives $6,10,15$ and 19 showed meaningful ferric reducing antioxidative activity. Structure-activity relationship revealed also the presence of similar activity pattern as in the DPPH assay. The presence of three hydroxy substituents on the phenyl ring might play the crucial role for ferric reducing antioxidant.

All compound showed significantly different FRAP values then $\mathrm{BHT}(P<0.05)$. From obtained results the four compounds 6, 10, 15 and 19 showed higher reducing ability then reference compound BHT $(7032.8 \pm 310.8,6884.7 \pm$ $109.5,5719.9 \pm 202.7$ and $4969.0 \pm 336.4 \mathrm{mmol} \mathrm{Fe}{ }^{2+} / \mathrm{mmol}_{c}$; respectively) while all other compounds exhibited much lower activity.

\section{CONCLUSION}

Within this manuscript, we present the design and synthesis of amidino substituted benzothiazole and benzimidazole derivatives directly attached to the phenyl 
ring with the variable number of hydroxy and methoxy groups. The prepared compounds were synthesized to explore their antioxidative activity in vitro.

Furthermore, our attention was to study SAR and the influence of the number of methoxy and hydroxy groups, the type of the heteroaromatic nuclei attached to the phenyl ring as well as the type of the amidino group placed either on the benzothiazole or benzimidazole moiety on the antioxidative activity.

The results obtained from the used antioxidative assays indicated that the variable number of hydroxy groups strongly influenced the antioxidative activity and reducing power of tested compounds, among which compounds 6, 10, 15 and 19 showed the most pronounced activity. Concerning the type of the amidino substituent placed at the heteroaromatic scaffold, it could be noticed, that in general unsubstituted amidino group had a greater impact on the increase of antioxidative activity. Furthermore, there was no significant difference in the antioxidative activity among benzothiazole and benzimidazole derivatives. All obtained results pointed out that the new series of synthesized derivatives demonstrated a high potential for expansion and optimization of their antioxidative activity.

Acknowledgment. This work has been supported by Croatian Science Foundation under the projects HRZZ-IP-2013-115596 (Synthesis and cytostatic evaluations of novel nitrogen heterocycles library) and under the project (HRZZ-IP-201409-8992) awarded to Tomislav Mašek. The authors have declared no conflict of interest.

\section{List of abbreviations}

DPPH - 1,1-diphenyl-picrylhydrazyl radical

ABTS - 2,2'-azinobis(3-ethylbenzthiazoline-6-sulphonic acid)

FRAP - ferric reducing/antioxidant power

ROS - reactive oxygen species

TBHQ - tert-butylhydroquinone

TMS - tetramethylsilane

DMSO - dimethylsulfoxide

TPTZ - tripyridyl-triazine

\section{REFERENCES}

[1] R. B. Silverman, The Organic Chemistry of Drug Design and Drug Action, Elsevier Academic Press, Amsterdam, 2004.

[2] W. D. Wilson, B. Nguyen, F. A. Tanious, A. Mathis, J. E. Hall, C. E. Stephens, D. W. Boykin, Curr. Med. Chem. Anticancer Agents 2005, 5, 389.

[3] M. Demeunynck, C. Bailly, W. D. Wilson, Small Molecule DNA and RNA Binders: From Synthesis to Nucleic Acid Complexes, Wiley-VCH, Weinheim, 2003.
[4] Y. Bansal, O. Silakari, Bioorg. Med. Chem. 2012, 20, 6208.

[5] K. Shah, S. Chhabra, S. K. Shrivastava, P. Mishra, Med. Chem. Res. 2013, 22, 5077.

[6] P. C. Sharma, A. Sinhmar, A. Sharma, H. Rajak, D. Pal Pathak, J. Enzyme Inhib. Med. Chem. 2013, 28, 240.

[7] L. Racané, V. Tralić-Kulenović, S. Kraljević Pavelić, I. Ratkaj, P. Peixoto, R. Nhili, S. Depauw, M. P. Hildebrand, M.-H. David-Cordonnier, K. Pavelić, G. Karminski-Zamola, J. Med. Chem. 2010, 53, 2418.

[8] M. Hranjec, I. Piantanida, M. Kralj, L. Šuman, K. Pavelić, G. Karminski-Zamola, J. Med. Chem. 2008, 51, 4899.

[9] L. Racane, R. Stojković, V. Tralić- Kulenović, H. Cerić, M. Đaković, K. Ester, A. Mišir Krpan, M. Radić Stojković, Eur. J. Med. Chem. 2014, 86, 406.

[10] M. Hranjec, M. Kralj, I. Piantanida, M. Sedić, L. Šuman, K. Pavelić, G. Karminski-Zamola, J. Med. Chem. 2007, 50, 5696.

[11] V. Lobo, A. Patil, A. Phatak, N. Chandra, Pharmacogn. Rev. 2010, 4, 118.

[12] S. B. Nimse, D. Pal, RSC Adv. 2015, 5, 27986.

[13] J. M. Matés, J. A. Segura, F. J. Alonso, J. Márquez, Arch. Toxicol. 2012, 86, 1649.

[14] E. R. Stadtman, Curr. Med. Chem. 2004, 11, 1105.

[15] N. Tailor, M. Sharma, Mini Rev. Med. Chem. 2013, $13,280$.

[16] A. Augustyniak, G. Bartosz, A. Čipak, G. Duburs, L. Horáková, W. Łuczaj, M. Majekova, A. D. Odysseos, L. Rackova, E. Skrzydlewska, M. Stefek, M. Štrosová, G. Tirzitis, P. Rimantas Venskutonis, J. Viskupicova, P. S. Vraka, N. Žarković, Free Radic. Res. 2010, 44, 1216.

[17] B. Zhou, B. Li, W. Yi, X. Bu, L. Ma, Bioorg. Med. Chem. Lett. 2013, 23, 3759.

[18] R. Likhar, P. Perumal, N. Kolhe, V. H. Bhaskar, P. Daroi, Int. J. Curr. Pharm. Res. 2015, 7, 34.

[19] L. Racanè, V. Tralić-Kulenović, Z. Mihalić, G. Pavlović, G. Karminski-Zamola, Tetrahedron 2008, 64, 11594.

[20] M. Hranjec, M. Kralj, I. Piantanida, M. Sedić, L. Šuman, K. Pavelić, G. Karminski-Zamola, J. Med. Chem. 2007, 50, 5696.

[21] I. Doulou, C. Kontogiorgis, A. E. Koumbis, E. Evgenidou, D. Hadjipavlou-Litina, K. C. Fylaktakidou, Eur. J. Med. Chem. 2014, 80, 145

[22] I. Gülçin, Z. Huyut, M. Elmastas, H.Y. Aboul-Enein. Arabian J. Chem. 2014, 3, 43.

[23] I. F. F. Benzie, J. J. Strain, Anal. Biochem. 1996, 239, 70.

[24] L. Racané, M. Sedić, N. Ilić, M. Aleksić, S. Kraljević Pavelić, G. Karminski-Zamola, Anti-Cancer Agents Med. Chem. 2017, 17, 57.

[25] T. Kulišić, A. Radonić, V. Katalinić, M. Miloš, Food Chem. 2004, 85, 633.

[26] K. Aksu, F. Topal, I. Gulcin, F. Tümer, S. Göksu, Arch. Pharm. Chem. Life Sci. 2015, 348, 446. 